\title{
Atheroembolic renal disease
}

Atheroembolic renal disease develops when atheromatous aortic plaques rupture, releasing cholesterol crystals into the small renal arteries. Embolisation often affects other organs, such as the skin, gastrointestinal system, and brain. Although the disease can develop spontaneously, it usually develops after vascular surgery, catheterisation, or anticoagulation. The systemic nature of atheroembolism makes diagnosis difficult. The classic triad of a precipitating event, acute or subacute renal failure, and skin lesions, are strongly suggestive of the disorder. Eosinophilia further supports the diagnosis, usually confirmed by biopsy of an affected organ or by the fundoscopic finding of cholesterol crystals in the retinal circulation. Renal and patient prognosis are poor. Treatment is mostly preventive, based on avoidance of further precipitating factors, and symptomatic, aimed to the optimum treatment of hypertension and cardiac and renal failure. Statins, which stabilise atherosclerotic plaques, should be offered to all patients. Steroids might have a role in acute or subacute progressive forms with systemic inflammation.

\section{Introduction}

Atheroembolic renal disease, sometimes referred to as renal cholesterol crystal embolisation, is a form of renal failure that is secondary to occlusion of renal arteries, arterioles, and glomerular capillaries with cholesterol crystals originating from atheromatous plaques of the aorta and other major arteries. Atheromatous material can be dislodged spontaneously or after intravascular trauma or anticoagulation. Typically, embolisation affects the kidneys, skin, gastrointestinal system, and brain. For this reason, atheroembolic renal disease is regarded as part of a multisystemic disorder. ${ }^{1-5}$ Atheroembolic disease, like thromboembolism, can complicate severe atherosclerosis. However, thromboembolism develops when a thrombus overlying an ulcerated plaque embolises and lodges in medium or large arteries, causing localised ischaemia.

Panum $^{6}$ first described atheroembolism in 1862, in the autopsy report of the Danish sculptor, Thorwaldsen, who died from a heart attack. In a coronary artery, a ruptured atheroma was identified, with atheromatous material filling the lumen distally. In English records, the first report of atheroembolism was made in 1926 by Benson, who reviewed three cases of coronary embolisation. In 1945, Flory ${ }^{1}$ proved the embolic origin of cholesterol crystals from eroded aortic atheromatous plaques. 40 years

\section{Search strategy and selection criteria}

We searched Medline (January, 1950-July, 2009), the Cochrane Library (January, 1993-July, 2009), and Embase (January, 1966-July, 2009) with the search terms "atheromatous embolism", "athero-embolism", "atheroembolism", "cholesterol crystals", "cholesterol embolism", "cholesterol embolization", or "cholesterol emboli". We also searched for these terms combined with "clinical trials", "prevention", "pathogenesis", "pathophysiology", "diagnosis", and "epidemiology". We had no language restrictions. We focused on original research, systematic reviews, and reviews or editorials. We also searched the reference lists of selected articles identified by the search strategy. The date of the last search was July 31, 2009. later, Fine and co-workers ${ }^{4}$ reviewed 221 cases of cholesterol crystal embolisation, underlining the low rate of antemortem clinical diagnosis. In the past two decades, atheroembolic renal disease has changed from being a pathological curiosity to a clinical syndrome. Some studies $^{8-12}$ provided an accurate assessment of the main characteristics of the disorder, including risk factors, causal events, clinical and laboratory findings, and renal and patient outcomes. Thus, this disease can now be thought of as a recognisable cause of renal disease, with diagnosis before death possible in most cases.

\section{Epidemiology}

Atheroembolic renal disease complicates widespread atherosclerosis in adults older than 60 years..$^{8-12}$ The disorder predominantly affects men and is rare in black people, possibly because of decreased recognition of the cutaneous lesions. ${ }^{13}$ Incidence is unknown. In clinical series, prevalence varies, probably because of sampling bias. In unselected autopsy series, ${ }^{14-17}$ the frequency of atheroemboli findings is low, ranging from $0.31 \%$ to $2 \cdot 40 \%$. However, in autopsy studies ${ }^{2,16-19}$ done in elderly patients and those who died after aortic surgery or aortography, researchers have reported an increased frequency, from $12 \%$ to $77 \%$. In two large renal biopsy studies, ${ }^{20,21}$ frequency of $1 \%$ was reported. However, in people older than age 60 years, the prevalence was $4 \cdot 0-6 \cdot 5 \% .^{22,23}$ In clinical practice, Mayo and Swartz ${ }^{9}$ have estimated that $5-10 \%$ of all cases of acute renal failure could be due to atheroembolism. ${ }^{9}$ Belenfant and colleagues $^{10}$ reported that $3 \%$ of patients admitted to a tertiary renal intensive care unit were diagnosed with atheroembolic renal disease..$^{10}$

\section{Pathophysiology}

Presence of diffuse aortic atherosclerosis is essential for development of atheroembolic renal disease. ${ }^{1-3}$ The usual risk factors for atherosclerosis (age older than 60 years, male sex, diabetes, hypertension, and cigarette smoking) are also major risk factors for atheroembolic renal disease $\mathrm{e}^{11,24,25}$ (panel 1). The atherosclerotic plaque, which is the main pathological entity of atherosclerosis,
Published Online April 9, 2010 DOI:10.1016/SO140 6736(09)62073-0

Faculty of Medicine, University of Brescia, Brescia, Italy (F Scolari MD); Azienda Ospedaliera Spedali Civili di Brescia, Seconda Divisione di Nefrologia e Dialisi, Presidio di Montichiari, Italy (F Scolari); and Division of Nephrology, Departments of Medicine and Community Health Sciences, University of Calgary, $A B$, Canada (P Ravani MD)

Correspondence to:

Dr Francesco Scolari, Division of Nephrology, Ospedale di Montichiari (Brescia) Via Ciotti 154, 25018 Montichiari (Brescia), Italy

fscolar@tin.it 
Panel 1: Population at risk for atheroembolic renal disease

- Male sex

- Older than age 60 years

- White people

- Hypertension

- Tobacco use

- Diabetes mellitus

- Atherosclerotic vascular disease

- Ischaemic cardiac disease

- Cerebrovascular disease

- Abdominal aortic aneurysm

- Peripheral vascular disease

- Ischaemic nephropathy

\begin{tabular}{|c|c|c|c|c|c|c|}
\hline & \multirow[t]{2}{*}{$\mathrm{n}$} & \multirow{2}{*}{ Spontaneous AERD (\%) } & \multicolumn{4}{|c|}{ latrogenic AERD } \\
\hline & & & $\begin{array}{l}\text { All causes } \\
(\%)\end{array}$ & $\begin{array}{l}\text { Angiography } \\
(\%)\end{array}$ & $\begin{array}{l}\text { CV surgery } \\
(\%)\end{array}$ & $\begin{array}{l}\text { Anticoagulation } \\
(\%)\end{array}$ \\
\hline Fine $^{4}$ & 221 & $153(69 \%)$ & $68(31 \%)$ & $39(18 \%)$ & $20(9 \%)$ & $30(14 \%)$ \\
\hline Lye $^{5}$ & 129 & $50(40 \%)$ & $79(60 \%)$ & $55(43 \%)$ & $7(5 \%)$ & $17(13 \%)$ \\
\hline Thadhani $^{8}$ & 52 & $0(0 \%)$ & $52(100 \%)$ & $50(96 \%)$ & $2(41 \%)$ & $19(37 \%)$ \\
\hline Belenfant ${ }^{10}$ & 67 & $3(4 \%)$ & $64(96 \%)$ & $57(85 \%)$ & $24(36 \%)$ & $51(76 \%)$ \\
\hline Scolari ${ }^{27}$ & 354 & $83(24 \%)$ & $271(76 \%)$ & $221(81 \%)$ & $69(25 \%)$ & $108(40 \%)$ \\
\hline
\end{tabular}

is characterised by a fibrous cap overlying a core containing necrotic cellular debris, foam cells, and lipids, including cholesterol crystals. Haemodynamic stress, inflammation, and haemorrhage can destabilise the plaque, which becomes friable and prone to erosion and rupture. ${ }^{26}$ The disease develops when the fibrous cap is denuded and portions of its core components break off, reaching the arterial bloodstream..$^{1-5}$ Plaque disruption caused by shear stress or intrinsic mechanisms leads to spontaneous atheroembolismthe most common form in the 1980s. ${ }^{4}$

Nowadays, atheroembolic renal disease tends to be iatrogenic, accounting for as many as $76-77 \%$ of cases in recent series,,$^{10-12,27,28}$ suggestive of the increased use of vascular procedures, anticoagulation, or thrombolysis ${ }^{4,11,24}$ (table 1). Thurlbeck and Castleman ${ }^{2}$ first recognised embolisation as a complication of vascular surgery causing plaque disruption during vessel incisions, cannulation, manual manipulation, or clamping. Embolisation can develop with any vascular procedure, such as abdominal aortic aneurysm resection and endovascular surgery, and aortoiliac, aortofemoral, and coronary artery bypass surgery. ${ }^{11,24}$ Angiography is the most common iatrogenic cause, accounting for up to $80 \%$ of cases. ${ }^{8,10,27}$ The disorder has been reported after aortography, renal, mesenteric, or coronary angiography, and percutaneous transluminal angioplasty with and without stenting. Mechanical trauma has a key role.
Guidewires and catheters can scrape aortic walls and disrupt atherosclerotic plaques.

Coronary angiography is the most common procedure causing embolism. ${ }^{24,27}$ However, the risk associated with coronary angiography might be underestimated in some study designs. Large retrospective studies reported incidence rates of one to two new cases per 1000 procedure-years..$^{15,29,30}$ Conversely, incidence of the disease after coronary angiography was several times higher than this rate, at 18-24 new cases per 1000 procedure-years in two prospective studies. ${ }^{31,32}$ Failure to search systematically for the disease in retrospective studies might be one possible explanation for this discrepancy. Since use of angiographic and endovascular procedures has increased exponentially during the past decades, and these procedures are now liberally extended to patients older than 60 years and with increasingly severe disease, the frequency of atheroembolic renal disease could reasonably be expected to rise in patients at risk.

Atheroembolic renal disease is an uncommon complication that is reported in patients given anticoagulants (warfarin, heparin, and low-molecular-weight heparin) or after thrombolytic therapy. ${ }^{3-5,8-12}$ These therapies can undermine the stabilising protective effects of thrombi on ulcerated plaques. ${ }^{33-36}$ In studies of patients with biopsy-proven atheroembolic renal disease, anticoagulation was regarded as a precipitating factor in $13-76 \%$ of cases..$^{4,5,8-12}$ However, in the absence of preceding invasive vascular procedures, anticoagulation was the sole triggering factor in only $7 \%$ of patients.

Once in the bloodstream, emboli lodge in small arteries of 150-200 mm in diameter. ${ }^{1-4}$ In studies $\mathrm{s}^{20,21,37-40}$ in people and animals, results suggest that emboli produce a microcrystalline angiitis, characterised by an endothelial inflammatory reaction developing in a stepwise pattern. Shortly after lodging, polymorpho-nuclear leukocytes and esosinophils infiltrate the affected arterioles, preceding mononuclear-cell infiltration and giant-cell formation. Thrombus formation then takes place, with endothelial proliferation and intimal fibrosis, leading to arterial obstruction. This final late phase occurs within 2-4 weeks. These processes generally result in ischaemia, sometimes in infarction, and rarely in necrosis. Because the crystals are insoluble in body fluids and not removable by phagocytosis, they persist indefinitely.

Histologically, cholesterol crystal emboli are identified in the lumen of arcuate and interlobular arteries as biconvex, needle-shaped, and empty clefts, referred to as ghost cells, because they dissolve during specimen processing. Rarely, small crystals lodge in the afferent arterioles and glomerular capillaries. The tissue damage caused by these crystal emboli is usually patchy. Glomerular and interstitial changes are mainly ischaemic, with a varying extent of glomerular obsolescence and interstitial fibrosis. In the early phases, areas of acute tubular necrosis can be identified. Cholesterol crystal 

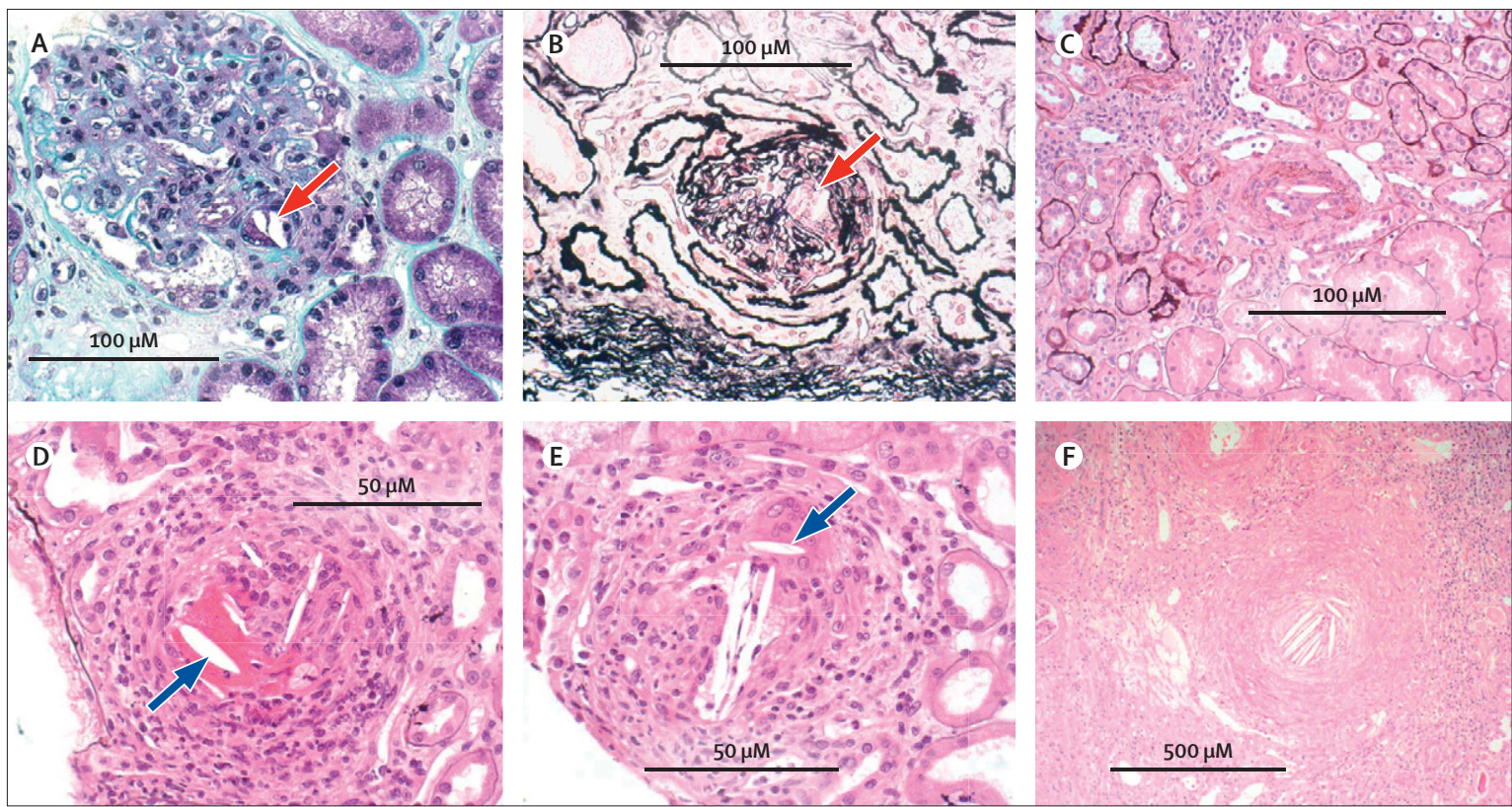

Figure 1: Renal cholesterol crystal emboli

Intraglomerular cholesterol crystals (arrows, A-B); cholesterol crystals in a renal arteriole (C); crystals in an arcuate artery with a pseudovasculitis inflammatory reaction (arrow, D); crystals in an arcuate artery, and encasement of a crystal by a giant cell (arrow, E); and organised occlusive crystals in a renal arteriole (F).

emboli are also identified in the skin, gastrointestinal tract, and muscle $\mathrm{e}^{11,20,21}$ (figures 1 and 2).

\section{Clinical features}

Clinical presentation of atheroembolic renal disease depends on the location and size of the embolising plaque, lodging sites, intensity and recurrence of the showering process, and pre-existing atherosclerotic disease. The ascending aorta and proximal aortic arch are the major sources of emboli to the cerebral and retinal arteries. Emboli to the visceral and renal arteries and to arteries of the legs and feet come from the descending thoracic and abdominal aorta. ${ }^{1-4}$ Subclinical or mild episodes can go completely unrecognised. However, massive embolisation can lead to a fulminant clinical picture, with multi-system involvement. ${ }^{8-12}$ (panel 2, table 2).

Kidney function can be affected acutely, subacutely, or in a chronic but slow, progressive way. ${ }^{8-12,24,25}$ A pronounced renal impairment with acute onset, arising within 1 week of a clear causal event, affects $20-30 \%$ of patients..$^{24,27}$ This abrupt renal impairment is due to massive migration of crystals, and is associated with evidence of embolisation elsewhere, affecting gastrointestinal and cutaneous systems in most cases. The most common form of atheroembolic renal disease is a subacute presentation, with progressive renal failure developing in a stepwise way during several weeks after an inciting event. Frock and co-workers ${ }^{41}$ reported that the mean interval between the arteriographic procedure and diagnosis of disease was 5.3 weeks. ${ }^{41}$ This long delay between the triggering event and the onset of renal insufficiency suggests a
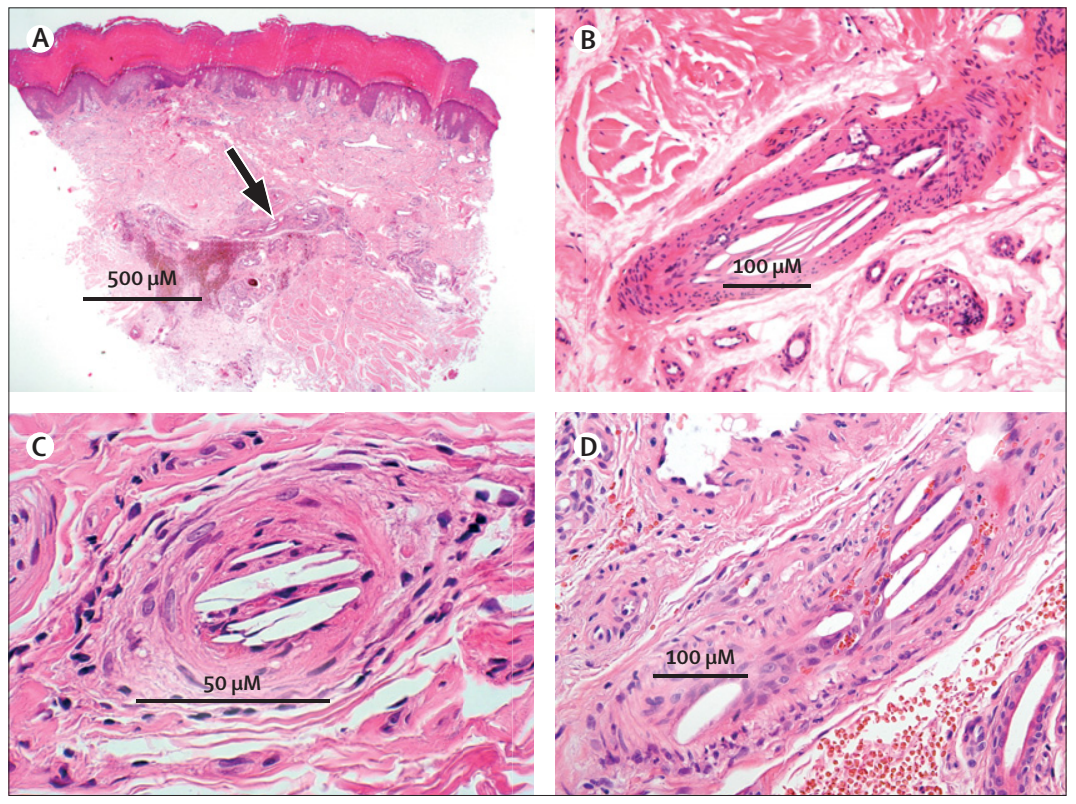

Figure 2: Cholesterol crystal emboli in derma arterioles

Low-power view of cholesterol crystals (arrow, A); and high-power showing clusters of cholesterol crystals (B-D).

causal role of recurrent emboli showers and inflammatory endothelial reaction. Another presentation is a chronic, slowly progressive renal impairment, often ascribed to nephroangiosclerosis or ischaemic nephropathy, which frequently co-cluster with cholesterol emboli. This mild form, with low-grade, clinically silent crystal migration is frequently underdiagnosed because extrarenal signs are absent and renal biopsy samples are not taken. ${ }^{42}$ 
The clinical course of renal failure can be variable. Dialysis is needed in $28-61 \%$ of patients with acute or subacute disease, with $20-30 \%$ partly recovering kidney function after a variable period of dialytic support. ${ }^{8-12}$ Recovery can be due to reversal of inflammation and resolution of concurrent acute tubular necrosis in

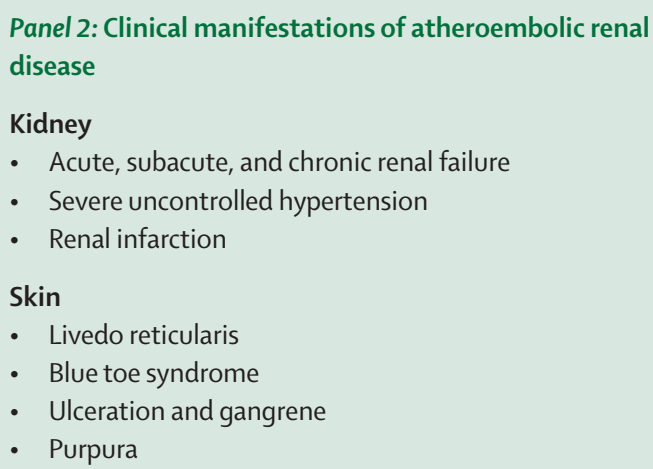

\begin{tabular}{|lcccclc|}
\hline & $\mathbf{n}$ & Skin lesions & Gl tract & CNS & Retinal emboli & Eosinophilia \\
\hline Fine $^{4}$ & 221 & $75(35 \%)$ & $21(10 \%)$ & 0 & $14(6 \%)$ & $22(73 \%)$ \\
Lye $^{5}$ & 129 & $55(43 \%)$ & $16(10 \%)$ & $15(12 \%)$ & $12(10 \%)$ & $57(71 \%)$ \\
Thadhani $^{8}$ & 52 & $26(50 \%)$ & $15(29 \%)$ & $12(23 \%)$ & $13(25 \%)$ & $11(22 \%)$ \\
Belenfant $^{10}$ & 67 & $60(90 \%)$ & $22(33 \%)$ & $3(4 \%)$ & $15(22 \%)$ & $39(59 \%)$ \\
Scolari2 $^{27}$ & 354 & $266(75 \%)$ & $43(12 \%)$ & $35(10 \%)$ & $24(7 \%)$ & $238(67 \%)$ \\
Gl=gastrointestinal. CNS=central nervous system. & & & \\
\hline Table 2: Clinical findings in atheroembolic renal disease &
\end{tabular}

ischaemic areas. Finally, atheroembolic renal disease can be associated with severe, uncontrolled hypertension. Renal infarction is a rare finding. ${ }^{20,21}$

Skin lesions are the most common extrarenal manifestations. Incidence of skin lesions is about 35\%. ${ }^{43}$ However, in most recent studies, ${ }^{8-12,44-46}$ the frequency ranged from $75 \%$ to $96 \%$. The classic skin lesions of this disease are blue toe syndrome and livedo reticularis. Affected toes are blue, cyanotic, painful, and cool to touch. The lesion might progress to ulceration, digital infarcts, or gangrene needing amputation. Patients often have palpable distal pulses. Livedo reticularis is a netlike, mottled red-blue discolouration usually on the lower legs and feet but sometimes on the buttocks and trunk. Blue toes and livedo reticularis are most evident on physical examination when the patient is upright. Rarely, the skin lesions are erythematous painful nodules or palpable purpura, requiring exclusion of leukocytoclastic vasculitis $^{44}{ }^{46}$ (figure 3).

The gastrointestinal system is the third most often affected system (18-48\% of patients), leading to substantial morbidity. ${ }^{8-12}$ Gastrointestinal tract involvement can take many forms. Patients can develop symptoms such as occult or frank blood loss and abdominal pain. Bleeding originates from any site, including the stomach, and results from superficial mucosal ulcerations or infarcts. Abdominal pain is caused by ischaemia of the bowel wall, potentially creating malabsorption and diarrhoea. Frank bowel infarction and perforation usually arise in the setting of catastrophic multiorgan disease. The liver, gallbladder, and pancreas are less commonly affected. ${ }^{47-51}$ Gastrointestinal effects are often overlooked. Diagnosis can be established by pathological examination, because the endoscopic appearance is nonspecific. $^{52}$ Patient outcomes in the presence of gastrointestinal disease are very poor. . $^{24,27}$

The true incidence of neurological embolisation is unknown and difficult to estimate, because the definitive diagnosis depends on evidence of embolisation to other organs. In the largest studies, neurological manifestations occurred in $4-23 \%$ of the patients with atheroembolic renal disease..$^{8-12,27}$ Mental confusion, transient ischaemic attack, focal neurological deficits, and amaurosis fugax are common findings. ${ }^{53-55}$ Retinal emboli can affect $6-25 \%$ of patients, ${ }^{56}$ representing a key to diagnosis (figure 4). ${ }^{8-12}$ Rarely, spinal cord infarction with leg paralysis develops..$^{57-60}$

Myositis and splenic infarcts are rare manifestations. ${ }^{61}$ Emboli deriving from the aortic root or the proximal segments of the coronary arteries are often associated with angina and sudden cardiac death. ${ }^{62,63}$ Pulmonary involvement proven by biopsy sample, characterised by diffuse alveolar haemorrhage mimicking systemic vasculitis, has been described in a few patients. The pathogenetic mechanisms of pulmonary haemorrhage remain poorly understood-a local inflammatory reaction elicited by emboli might have a role. ${ }^{64-67}$ In autopsy studies, subclinical involvement of adrenals, testes, prostate, 

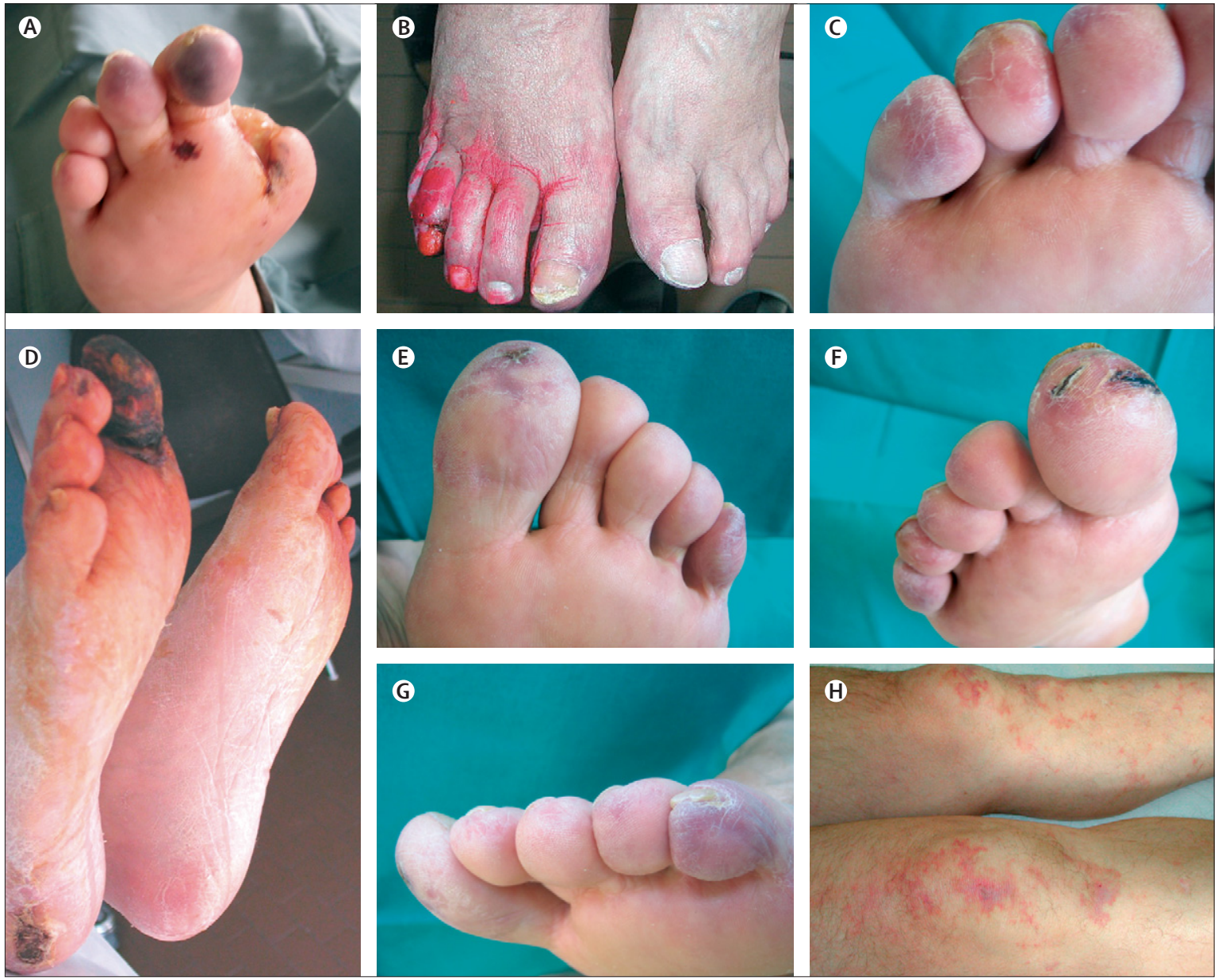

Figure 3: Skin lesions in atheroembolic renal disease

Blue toe syndrome of variable severity $(A-G)$; and purpuric lesions $(H)$.

thyroid, and virtually any organ has been reported $\mathrm{d}^{4,17}$ (figure 5). Finally, several non-specific findings can accompany the course of atheroembolic renal disease, such as fever, weight loss, myalgias, and headache, suggesting the systemic nature of the disease. .8-12,20,21 $^{-12}$

\section{Laboratory findings}

Laboratory test findings are non-specific, such as anaemia, leukocytosis, thrombocytopenia, and raised concentrations of inflammatory markers (ESR or C-reactive protein). Results of urinalysis are typically benign, with few cells and a minimum amount of proteinuria-a finding consistent with ischaemic damage. ${ }^{4,4-12}$ Nephrotic-range proteinuria has been described ${ }^{11,6,69}$ in a few patients with superimposed biopsy-proven focal glomerulosclerosis or diabetic nephropathy. Eosinophilia is an abnormal laboratory finding that frequently occurs during the acute phase of the disease, thereby showing immunological activation at the surface of the exposed emboli. ${ }^{8-12}$ In a previous review, Kasinath and co-workers ${ }^{70}$ described eosinophilia in $80 \%$ of cases of atheroembolic renal disease. Eosinophilia was typically transient, ranging from
$6 \%$ to $18 \%$ in a recent study. ${ }^{70} 67 \%$ of 354 patients had an eosinophil count higher than 500 cells per $\mu \mathrm{L}$, confirming that eosinophilia can help establish the diagnosis. ${ }^{27}$

Other features can include hypocomplementaemia, ${ }^{71}$ which has been reported in $39 \%$ of patients in one study. ${ }^{5}$ However, this finding was not consistent with results of other studies. . $^{-12}$ Abnormal laboratory findings can implicate specific organs: increased concentrations of hepatic enzymes suggest liver disease, and raised amylase and lipase concentrations pancreatic disease; raised creatinine phosphokinase concentration are suggestive of myositis, and increased serum aspartate aminotransferase and lactate dehydrogenase concentrations are suggestive of renal infarction. ${ }^{410,11}$ Finally, a few studies ${ }^{927,72}$ reported proportions of cholesterolaemia in patients with atheroembolic renal disease, with total cholesterol higher than $5 \cdot 2 \mathrm{mmol} / \mathrm{L}$ ranging from $23 \%$ to $27 \%$, and $64 \%$.

\section{Diagnosis}

Because atheroembolisation is ubiquitous, atheroembolic renal disease can mimic several different clinical syndromes. ${ }^{21,73}$ Knowledge of the risk factors and 


\section{Seminar}
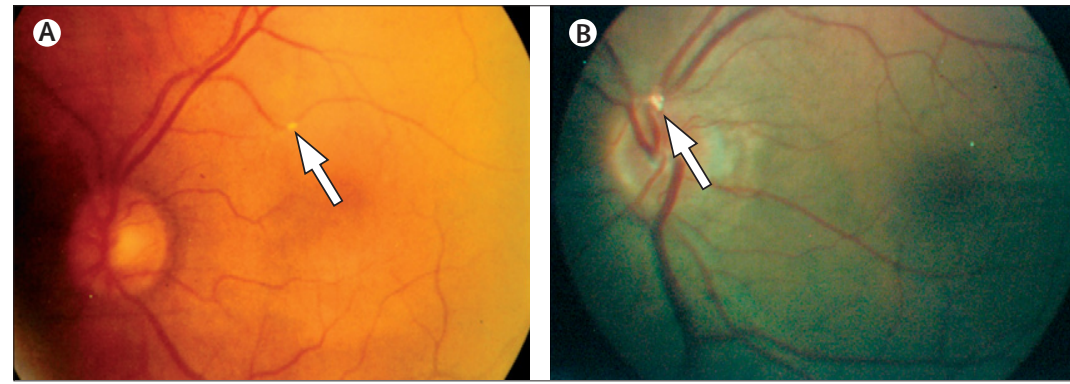

Figure 4: Retinal cholesterol crystal emboli

recognition of the variable clinical presentations can heighten the likelihood of making a premortem diagnosis..$^{8-12,27}$ The typical patient at risk is a man older than age 60 years with known atherosclerotic disease presenting with a clinical triad of a precipitating event, acute or subacute renal failure, and typical skin findings. Presence of eosinophilia should raise the level of suspicion. Renal biopsy is regarded as the definitive method for diagnosis. Renal samples yield a positive diagnosis in more than $75 \%$ of patients with acute or subacute renal failure. ${ }^{74}$ However, taking a renal biopsy sample is not always feasible, especially in sick patients. Taking a biopsy sample of skin lesions, a straightforward, and relatively non-invasive procedure, has a high diagnostic yield approaching 92\%. ${ }^{41}$ Feet and lower legs are also the best sites for biopsy. ${ }^{7475}$ Occasionally, histological confirmation can be made from biopsy samples from less likely target organs, such as gastrointestinal tissues. ${ }^{24}$

Tissue biopsy sampling is not necessary when cholesterol crystals are seen in the retinal vessels (Hollenhorst plaques), which can be identified in 10-25\% of cases. ${ }^{8-12}$ For this reason, fundoscopy examination should never be omitted. Diagnosis by tissue sample is not needed in the presence of the classic triad. For patients with the classic triad, atheroembolic renal disease can be diagnosed solely on a clinical basis. ${ }^{8-12,27}$ Thus, renal biopsy sampling can be avoided in some patients. Conversely,
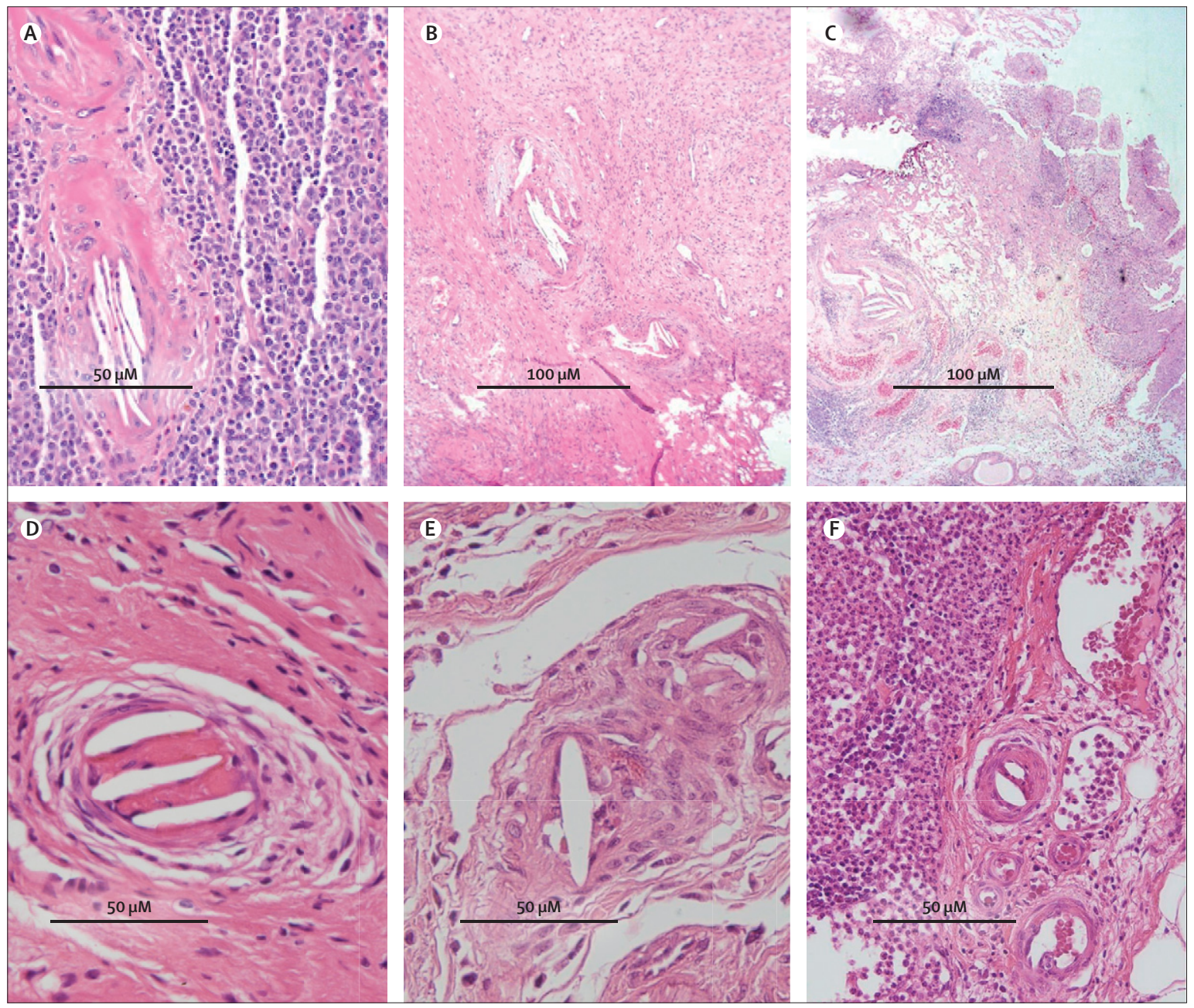

Figure 5: Cholesterol crystal in extrarenal sites

Spleen (A); prostate (B); bladder (C); stomach (D); ileum (E); and lymph node (F). 
renal biopsy is crucial for diagnosis of cases with chronic, smouldering forms of this disease, which are frequently spontaneous and usually develop in the absence of evident extrarenal signs ${ }^{11,24,27}$ (panel 3 and table 3).

Differential diagnoses are contrast nephropathy, smallvessel vasculitis, drug-induced interstitial nephritis, and subacute bacterial endocarditis. In contrast nephropathy, the rise in plasma creatinine concentrations happens immediately after the radiographic study, and the course is different-creatinine concentration peaks within a few days after exposure and returns to or near baseline after 10-14 days. ${ }^{11,20,21,24}$ Extrarenal emboli, if present, enable diagnosis of atheroembolic renal disease. The disease can be distinguished from systemic vasculitis by urinalysis, typically characterised by the absence of proteins and blood cells in atheroembolic renal disease as opposed to the nephritic sediment of vasculitis, and by an autoimmune screening including antineutrophil cytoplasmic antibodies testing. ${ }^{11,24}$ The temporal relation between use of an offending drug and occurrence of fever, skin rash, eosinophilia, and acute renal failure strongly suggests acute tubulointerstitial nephritis, a diagnosis that should be confirmed by renal biopsy. Presence of subacute bacterial endocarditis needs to be ruled out, especially if hypocomplementaemia is present. Signs of systemic infection and echocardiographic findings exclude atheroembolic renal disease.

\section{Embolic disease in renal allografts}

Atheroembolic renal disease in renal allografts is rare, with a frequency ranging from $0 \cdot 39 \%$ to $0 \cdot 47 \% .^{76,77}$ So far, only 45 cases have been reported-too few to define the natural history of the disorder. ${ }^{76-85}$ Such disease is probably underestimated because of the use of small needles for taking biopsy samples and sampling error. Atheroemboli causing injury to the renal allograft can arise from either the donor or the recipient vessels. Two distinct clinical presentations have been described. The first is an early atheroembolic renal disease, with emboli frequently released from the donor's arteries before or during organ harvesting. More rarely, early embolisation originates from the recipient's atheromatous vessels during the anastomosis. The early form is usually associated with primary non-function, and the embolic disease is confined to the allograft. The second form is a late clinical presentation, which can arise years after transplantation in stable grafts. In this case, emboli originate from the recipient's vessels. The disease is usually associated with recipitating factors, and in some cases shows features of a systemic disorder.

Renal outcomes of early and late atheroembolic disease seem to differ. Graft loss is frequently associated with early disease, in which the emboli originate from the donor. Prognosis can be especially poor in the setting of primary non-function. Conversely, late manifestations usually have a good outcome, with graft recovery in most cases..$^{11,76-78}$ The reason for this difference could be
Panel 3: Diagnostic criteria for atheroembolic renal disease

\section{Patient at risk}

- Men older than 60 years

- Longstanding hypertension

- Tobacco use

- Diffuse atherosclerotic disease

2 Presence of classic triad

- Exposure to precipitating factor

- Acute or subacute renal failure

- Peripheral signs of embolisations (eg, blue toe syndrome)

3 Gastrointestinal or neurological effects and eosinophilia

- Should raise the level of suspicion

4 Histological confirmation

- Pathological specimens obtained from the kidney, skin, or muscle

- Skin biopsy sample

- Simple, low-invasive procedure with high diagnostic yield

- Tissue biopsy sample not necessary in presence of retinal emboli

- Tissue sample not needed in presence of classic triad

- Renal biopsy is crucial to diagnosis of chronic forms of atheroembolic renal disease

\begin{tabular}{|c|c|c|c|c|c|c|c|c|}
\hline & \multirow[t]{2}{*}{$n$} & \multicolumn{5}{|c|}{ Biopsy sample } & \multirow[t]{2}{*}{ Clinical } & \multirow[t]{2}{*}{ Postmortem } \\
\hline & & Kidney & Skin & Muscle & Gl tract & Other & & \\
\hline Fine $^{4}$ & 221 & $15(7 \%)$ & $18(8 \%)$ & $18(8 \%)$ & $5(2 \%)$ & $13(6 \%)$ & 0 & $152(69 \%)$ \\
\hline Thadhani $^{8}$ & 52 & $16(31 \%)$ & $9(17 \%)$ & $11(21 \%)$ & 0 & 0 & $5(9 \%)$ & $11(22 \%)$ \\
\hline Belenfant ${ }^{10}$ & 69 & $24(36 \%)$ & $15(22 \%)$ & 0 & $12(18 \%)$ & 0 & $16(24 \%)^{*}$ & 0 \\
\hline Scolari ${ }^{27}$ & 354 & $63(18 \%)$ & $13(37 \%)$ & 0 & $4(1 \%)$ & 0 & $14(42 \%)^{*}$ & $7(2 \%)$ \\
\hline
\end{tabular}

attributable to extensive embolisation in an atherosclerotic donor during organ procurement. Because the tendency to accept donors and recipients older than age 60 years and to use marginal donors with advanced atherosclerosis has increased, atheroembolic renal disease in renal allografts will probably be encountered more often than previously. To reduce the risk of atheroemboli, an accurate assessment of organ donors should be done. At the time of organ procurement, manipulation of the aorta should be kept to a minimum, mobilising the kidneys without cross-clamping the aorta, as done for living-related donors. Finally, the number of invasive vascular work-up procedures should be kept to a minimum. ${ }^{11,77}$

\section{Treatment}

For patients with atheroembolic renal disease, the aim of treatment is to restrict the extent of ischaemic damage and prevent recurrent embolisation. No definitive treatment has been established. Therapeutic measures are mostly preventive and supportive. ${ }^{8-12,24-27}$ Mainstays of 
Panel 4: Treatment of atheroembolic renal disease

- Major goal

- Restrict extent of the ischaemic damage

- Prevent recurrent embolisation

- No definitive treatment has been established

- Therapeutic modalities are mostly preventive and supportive

- Preventive treatment aims to avoid further precipitating factors

- Withdrawal of anticoagulant therapy

- Avoid any new radiological or aortic surgery procedure

- Medical intervention

- Mostly symptomatic

- Aggressive treatment of associated hypertension and cardiac and renal failure

- Optimum type of dialysis (peritoneal dialysis vs haemodialysis) unknown

- Adequate nutritional support when needed

- Steroids in patients with multisystem involvement and recurrent, progressive disease

- Statins should be offered to all patients with atheroembolic renal disease

\begin{tabular}{|lrllll|}
\hline & $\mathbf{n}$ & $\begin{array}{l}\text { Renal failure } \\
\text { needing dialysis }\end{array}$ & $\begin{array}{l}\text { Recovery of dialysis- } \\
\text { dependent renal failure }\end{array}$ & $\begin{array}{l}\text { Maintainence dialysis } \\
\text { (end of follow-up) }\end{array}$ & $\begin{array}{l}\text { 1-year } \\
\text { mortality }\end{array}$ \\
\hline Fine $^{4}$ & 221 & $62(28 \%)$ & $13(21 \%)$ & 0 & $179(81 \%)$ \\
Lye $^{5}$ & 129 & $52(40 \%)$ & $13(26 \%)$ & 0 & $83(64 \%)$ \\
Thadhani $^{8}$ & 52 & $23(44 \%)$ & $7(32 \%)$ & 0 & $45(87 \%)$ \\
Belenfant $^{10}$ & 67 & $41(61 \%)$ & $16(39 \%)$ & $23(35 \%)$ & $9(13 \%)$ \\
Scolari $^{27}$ & 354 & $11(33 \%)$ & $33(28 \%)$ & $88(25 \%)$ & $60(17 \%)$ \\
\hline Table 4: Renal and patients outcome in atheroembolic renal disease \\
\hline
\end{tabular}

preventive treatment are based on restriction of exposure to precipitating factors, such as withdrawal of anticoagulant therapy after carefully considering the pros and cons of these drugs, and avoidance of any additional radiological or aortic surgery procedure. Medical intervention in established cases is mostly for symptom management, and should aim to provide optimum treatment of associated hypertension and cardiac and renal failure. Cardiac dysfunction and hypertension should be aggressively treated. In some cases, renal replacement therapy is needed for uraemia and fluid balance control in patients that are unresponsive to high-dose diuretic therapy. ${ }^{10-12,24,27,74}$ The optimum type of dialysis is not known. Both peritoneal dialysis and haemodialysis have been used. ${ }^{10,11,86,87}$ Peritoneal dialysis might improve the chances of renal recovery because it does not need anticoagulation. In the absence of intestinal ischaemia and malnutrition, peritoneal dialysis should be the preferred treatment modality. However, haemodialysis without or with only minimal anticoagulation is not contraindicated. In most severe cases, during the acute phase, adequate nutritional support can be provided by parenteral nutrition. ${ }^{10}$
No clinical trials of treatment for patients with atheroembolic renal disease have been done. However, results of some studies of steroids and statins suggest that they might have a potential role. Possible benefits of steroids have been reported in small series. ${ }^{88-90}$ Belenfant and co-workers ${ }^{10}$ used low-dose steroid $(0.3 \mathrm{mg} / \mathrm{kg})$ in 18 patients with relapsing disease who had improved symptoms and nutritional intake. ${ }^{10}$ Results of other series ${ }^{72}$ have shown beneficial effects with high doses of steroids. Conversely, other reports ${ }^{4}$ have shown little or marginal benefit from steroid treatment. In a prospective study ${ }^{27}$ of 354 patients with atheroembolic renal disease, steroids were not associated with improved renal or patient outcomes. Thus, steroid use is still controversial, although it could have a role in patients with multi-system involvement, recurrent and progressive disease, and systemic inflammation.

Interest has grown in the potential protective role of statins. Occasional cases of atheroembolic renal disease have responded to statins..$^{91}$ In a prognostic study, ${ }^{12}$ patients assigned statin therapy had a lowered risk of development of endstage renal disease. A large prospective study ${ }^{27}$ confirmed this finding. Statins had a beneficial effect even when statin therapy was started after diagnosis of atheroembolic renal disase. The protective effect of statins could be attributable to plaque stabilisation and regression through lipid-lowering and anti-inflammatory mechanisms. Plaque stabilisation might result in a lowered risk for further embolisation. However, the observational nature of these data precludes establishment of causality. Despite these limitations, use of statins could be justifiable (panel 4). Finally, there are isolated reports of successful therapy in small numbers of patients given iloprost, pentoxifylline, and LDL apheresis. These approaches have yet to be tested in controlled studies. Other drugs such as antiplatelet agents and low-molecular weight dextran do not provide any benefit. ${ }^{11,24}$

Surgical removal of the source of emboli could offer a definitive treatment option. However, surgical treatment is often not feasible and is associated with substantial morbidity. A clear embolic source is difficult to identify. Additionally, patients are frequently too weak for surgery. Finally, the necessary aortic clamping during surgery would induce major risk for recurrence. A surgical approach was assessed by Keen and colleagues ${ }^{92}$ in a prospective study of 100 patients. They concluded that surgery can be an option when the emboli source is located in the infrarenal aorta. If supra-renal aorta is implicated, morbidity and mortality is increased because of the risk for visceral and renal atheroembolisation. Thus, surgical intervention should be regarded as a rescue therapy, and restricted to life-threatening situations. To eliminate the embolic source, percutaneous transluminal angioplasty and stent placement have been undertaken in a few patients with aortoiliac and femoral artery sources of embolisation. ${ }^{93,94}$ These endovascular procedures could also be associated with a high risk of further embolisation, 
possibly occurring as a consequence of vessel injury caused by catheters and guide wires within the aorta (type 1 embolisation) or by active plaque disruption during balloon dilation or stenting (type 2 embolisation)..$^{95}$ Definitive recommendations for use of this approach cannot yet be made.

Primary prevention of atheroembolic renal disease is important, restricting indications for angiography and surgical procedures in atherosclerotic patients. Noninvasive diagnostic methods, such as MR angiography or computer-assisted tomographic angiography, could in part obviate the risk for catheter-induced embolisation. During endovascular procedures, use of proper and cautious techniques, including a so-called no touch technique avoiding direct trauma of the catheter tip to the atheromatous vessel wall might reduce risk of embolisation. Finally, the potential application of embolic protection devices, which removes atheromatous debris, could help keep risk of embolisation to a minimum.

\section{Outcomes}

\section{Renal survival}

Few outcome studies have been done in patients with atheroembolic renal disease. Renal prognosis is poor. Lye and co-workers ${ }^{5}$ reported that $40 \%$ of 129 patients needed dialysis, of whom only $21 \%$ recovered sufficient renal function to stop dialysis. In a series, Thadhani and colleagues $^{8}$ reported that $44 \%$ of 52 patients underwent dialysis. Belenfant and co-workers ${ }^{10}$ reported that dialysis was needed in $61 \%$ of 67 patients, with 13 patients regaining sufficient renal function to be free of dialysis. In a prospective study, ${ }^{12} 37 \%$ of 95 patients needed dialysis, 14 recovered sufficient renal function to stop dialysis, and 23 remained dialysis dependent (24\%; table 4$)$. The most important predictors of endstage renal disease needing permanent dialysis therapy were pre-existing chronic renal insufficiency and longstanding hypertension. Another major finding was a protective benefit of statins - patients given statin treatment had a significantly lower risk for development of end-stage renal disease than did those not given statins. ${ }^{12}$

\section{Patient survival}

Atheroembolic renal disease is generally associated with high mortality. An $81 \%$ mortality rate was reported by Fine and co-workers at 1 year. ${ }^{4}$ Lye and colleagues ${ }^{5}$ reported a $64 \%$ mortality rate at 1 year. The major cause of death was cardiovascular. A favourable clinical outcome, with a 1-year mortality rate of $13 \%$, was reported by Belenfant, ${ }^{10}$ with an aggressive therapeutic approach. The protocol was based on avoidance of anticoagulation and aortic manipulating procedures, good control of hypertension and heart failure, dialytic therapy, and adequate nutritional support. Benefits of similar supportive care were confirmed in a prospective study ${ }^{27}$ of 354 patients, with an 83\% 1-year patient-survival rate (table 4). Predictors of increased risk for death were diabetes and heart failure, baseline levels of renal function, acute or subacute renal failure, and development of extrarenal manifestations, especially affecting the gastrointestinal tract (relative risk [RR] 2.57, 95\% CI 1.69-3.93). Finally, previous statin use was associated with improved patient survival (RR 0.44 , $0 \cdot 28-0 \cdot 67)$. Notably, the same predictors were associated with an increased risk for endstage renal disease, suggesting a common underlying mechanism for renal and cardiovascular events. ${ }^{27}$

\section{Future research}

Atheroembolic renal disease has become a recognisable cause of renal failure. However, its incidence in patients at risk remains unknown, and diagnosis depends on how much experience centres have had with this disease. Ideally, a systematic search for signs and symptoms of the disease in populations undergoing aortic procedures would provide information to answer this important question. In terms of prognosis of established cases, avoidance of known precipitating factors and individualised supportive measures could substantially improve clinical outcome. ${ }^{96,97}$ However, the disorder greatly affects patient and renal survival, and further research is urgently needed to alter its clinical course. Three different areas of clinical investigation need to be explored.

The first is the potential benefit of specific therapies, such as steroids and statins. A reactive inflammation around the crystals is suggested by eosinophilia, a cytokine-mediated occurrence, ${ }^{98}$ and has a role in causing or worsening ischaemia. However, anti-inflammatory benefits might be counterbalanced by harmful effects of steroids on the cardiovascular system. For this reason, benefits and harms of steroid treatment should be tested in clinical trials. The protective role of statins ${ }^{12,27}$ should also be confirmed by intervention studies. Atheroembolic renal disease alone represents an indication for standard statin therapy. Intensive statin therapy seems to provide more cardiovascular protection than does standard therapy in patients with coronary disease, ${ }^{99,100}$ and whether this effect applies to patients with atheroembolic renal disease needs to be tested.

The second area of research is the modality of renal replacement therapy in patients needing dialysis. Clinical trials are necessary to test whether standard haemodialysis needing anticoagulation is associated with worse patient and renal outcomes than is peritoneal dialysis. Last, the prognostic effect of antiembolic devices during endovascular procedures on the evolution of atheroembolic renal disease is unknown. This approach is the standard of care during carotid artery stenting because it reduces procedure-related embolic strokes. ${ }^{101}$ Such protection devices have also been used during renal artery stenting with promising results. ${ }^{102}$ Insufficient information is available to test the pros and cons of a broadened use to reduce short-term and long-term atheroembolic complications of endovascular procedures. 
Contributors

Both authors contributed equally to the design and writing of this Seminar.

Conflicts of interest

We declare that we have no conflicts of interest.

\section{Acknowledgments}

We thank R Tardanico (University of Brescia, Italy) for providing figure 1, Facchetti (Brescia, Italy) for figure 2, C Rollino (Turin, Italy) for figure 4A, A Marciello (Turin, Italy) for figure 4B, R Tardanico for figure 5, and B I Barrett (Memorial University of Newfoundland, Canada) for his critical comments on this report and H Benediktsson (University of Calgary, Canada) for his assistance with the histology section preparation.

References

1 Flory CM. Arterial occlusions produced by emboli from eroded aortic atheromatous plaques. Am J Pathol 1945; 21: 549-65.

2 Thurlbeck WM, Castleman B. Atheromatous emboli to the kidneys after aortic surgery. N Engl J Med 1957; 257: 442-47.

3 Kassirer JP. Atheroembolic renal disease. N Engl J Med 1969; 280: 812-18.

4 Fine MJ, Kapoor W, Falanga V. Cholesterol crystal embolization: a review of 221 cases in the English literature. Angiology 1987; 38: 769-84.

5 Lye WC, Cheah JS, Sinniah R. Renal cholesterol embolic disease. Case report and review of the literature. Am J Nephrol 1993; 13: 489-93.

6 Panum PL. Experimentell Beitrage zur Lehre von der Embolie. Virchows Arch 1862; 25: 308-10.

7 Benson RL. The present status of coronary arterial disease. Arch Pathol Lab Med 1926; 2: 876-916.

8 Thadhani RI, Camargo CA Jr, Xavier RJ, Fang LS, Bazari H. Atheroembolic renal failure after invasive procedures. Natural history based on 52 histologically proven cases. Medicine 1995; 74: 350-58.

9 Mayo RR, Swartz RD. Redefining the incidence of clinically detectable atheroembolism. Am J Med 1996; 100: 524-29.

10 Belenfant X, Meyrier A, Jacquot C. Supportive treatment improves survival in multivisceral cholesterol crystal embolism. Am J Kidney Dis 1999; 33: 840-50.

11 Scolari F, Tardanico R, Zani R, et al. Cholesterol crystal embolism: A recognizable cause of renal disease. Am J Kidney Dis 2000; 36: 1089-109.

12 Scolari F, Ravani P, Pola A, et al. Predictors of renal and patient outcomes in atheroembolic renal disease: a prospective study. J Am Soc Nephrol 2003; 14: 1584-90.

13 Saklayen MG. Atheroembolic renal disease: preferential occurrence in whites only. Am J Nephrol 1989; 9: 87-88.

14 Cross S. How common is cholesterol embolism? J Clin Pathol 1991; 44: 859-61.

15 Drost H, Buis B, Haan D, Hillers JA. Cholesterol embolism as a complication of left heart catheterisation. Report of seven cases. Br Heart J 1984; 52: 339-42.

16 Kealy WF. Atheroembolism. J Clin Pathol 1978; 31: 984-89.

17 Moolenaar W, Lamers CB. Cholesterol crystal embolization in the Netherlands. Arch Intern Med 1996; 156: 653-57.

18 Ramirez G, O'Neill WM, Lambert R, Bloomer HA. Cholesterol embolization: a complication of angiography. Arch Intern Med 1978; 138: 1430-32.

19 Gore I, Collins D. Spontaneous atheromatous embolization. Review of the literature and a report of 16 additional cases. Am J Clin Pathol 1960; 33: 416-26.

20 Jones DB, Iannaccone PM. Atheromatous emboli in renal biopsies. An ultrastructural study. Am J Pathol 1975; 78: 261-76.

21 Lie JT. Cholesterol atheromatous embolism. The great masquerader revisited. Pathol Annu 1992; 2: 17-50.

22 Preston RA, Stemmer CL, Materson BJ, Perez-Stable E, Pardo V. Renal biopsy in patients 65 years of age or older. An analysis of the results of 334 biopsies. J Am Geriatr Soc 1990; 38: 669-74.

23 Stone W, Fogo A. Hypertension and renal disease in the elderly. Boston, MA: Blackwell, 1992.

24 Meyrier A. Cholesterol crystal embolism: diagnosis and treatment. Kidney Int 2006; 69: 1308-12.

25 Modi K, Rao V. Atheroembolic renal disease. J Am Soc Nephrol 2001; 12: 1781-87.
26 Arroyo LH, Lee RT. Mechanisms of plaque rupture: mechanical and biologic interactions. Cardiovasc Res 1999; 41: 369-75.

27 Scolari F, Ravani P, Gaggi R, et al. The challenge of diagnosing atheroembolic renal disease: clinical features and prognostic factors. Circulation 2007; 116: 298-304.

28 Mittal BV, Alexander MP, Rennke HG, Singh AK. Atheroembolic renal disease: a silent masquerader. Kidney Int 2008; 73: 126-30.

29 Johnson L, Esente P, Giambartolomei A, et al. Peripheral vascular complications of coronary angioplasty by the femoral and brachial techniques. Cathet Cardiovasc Diagn 1994; 31: 165-72.

30 Nasser T, Mohler E third, Wilensky R, Hathaway D. Peripheral vascular complications following coronary interventional procedures. Clin Cardiol 1995; 18: 609-14.

31 Fukumoto Y, Tsutsui H, Tsuchihashi M, Masumoto A, Takeshita A. The incidence and risk factors of cholesterol embolization syndrome, a complication of cardiac catheterization: a prospective study J Am Coll Cardiol 2003; 42: 211-16.

32 Saklayen MG, Gupta S, Suryaprasad A, Azmeh W. Incidence of atheroembolic renal failure after coronary angiography. A prospective study. Angiology 1997; 48: 609-13.

33 Rudnick MR, Berns JS, Cohen RM, Goldfarb S. Nephrotoxic risks of renal angiography: contrast media-associated nephrotoxicity and atheroembolism - a critical review. Am J Kidney Dis 1994; 24: 713-27.

34 Feder W, Auerbach R. "Purple toes": an uncommon sequela of oral coumarin drug therapy. Ann Intern Med 1961; 55: 911-17.

35 Moldveen-Geronimus M, Merriam JC Jr. Cholesterol embolization. From pathological curiosity to clinical entity. Circulation 1967; 35: 946-53.

36 Hitti WA, Wali RK, Weinman EJ, Drachenberg C, Briglia A. Cholesterol embolization syndrome induced by thrombolytic therapy. Am J Cardiovasc Drugs 2008; 8: 27-34.

37 Eliot RS, Kanjuh VI, Edwards JE. Atheromatous Embolism. Circulation 1964; 30: 611-18.

38 Snyder HE, Shapiro JL. A correlative study of atheromatous embolism in human beings and experimental animals. Surgery 1961; 49: 195-204.

39 Gore I, McCombs HL, Lindquist RL. Observations on the fate of cholesterol emboli. J Atheroscler Res 1964; 4: 527-35.

40 Warren BA, Vales O. The ultrastructure of the stages of atheroembolic occlusion of renal arteries. Br J Exp Pathol 1973; 54: 469-78.

41 Frock J, Bierman M, Hammeke M, Reyes A. Atheroembolic renal disease: experience with 22 patients. Nebr Med J 1994; 79: 317-21.

42 Zucchelli $\mathrm{P}$, Zuccalà $\mathrm{A}$. The diagnostic dilemma of hypertensive nephrosclerosis: the nephrologist's view. Am J Kidney Dis 1993; 21: 87-91.

43 Falanga V, Fine MJ, Kapoor WN. The cutaneous manifestations of cholesterol crystal embolization. Arch Dermatol 1986; 122: 1194-98.

44 Liew YP, Bartholomew JR. Atheromatous embolization. Vasc Med 2005; 10: 309-26.

45 Donohue KG, Saap L, Falanga V. Cholesterol crystal embolization: an atherosclerotic disease with frequent and varied cutaneous manifestations. J Eur Acad Dermatol Venereol 2003; 17: 504-11.

46 Jucgla A, Moreso F, Muniesa C, Moreno A, Vidaller A. Cholesterol embolism: still an unrecognized entity with a high mortality rate. J Am Acad Dermatol 2006; 55: 786-93.

47 Ben-Horin S, Bardan E, Barshack I, Zaks N, Livneh A. Cholesterol crystal embolization to the digestive system: characterization of a common, yet overlooked presentation of atheroembolism. Am J Gastroenterol 2003; 98: 1471-79.

48 Moolenaar W, Lamers CB. Cholesterol crystal embolization and the digestive system. Scand J Gastroenterol Suppl 1991; 188: 69-72.

49 Moolenaar W, Lamers CB. Cholesterol crystal embolisation to the alimentary tract. Gut 1996; 38: 196-200.

50 Moolenaar W, Lamers C. Gastrointestinal blood loss due to cholesterol crystal embolization. J Clin Gastroenterol 1995; 21: 220-23.

51 Moolenaar W, Lamers C. Cholesterol crystal embolization to liver, gallbladder, and pancreas. Dig Dis Sci 1996; 41: 1819-22.

52 Paraf F, Jacquot C, Bloch F, de Montpreville V, Bruneval P. Cholesterol crystal embolization demonstrated on GI biopsy. Am J Gastroenterol 2001; 96: 3301-04. 
53 Beal M, Williams RS, Richardson EP Jr, Fisher CM. Cholesterol embolism as a cause of transient ischemic attacks and cerebral infarction. Neurology 1981; 31: 860-65.

54 Price DL, Harris J. Cholesterol emboli in cerebral arteries as a complication of retrograde aortic perfusion during cardiac surgery. Neurology 1970; 20: 1209-14.

55 Masuda J, Yutani C, Ogata J, Kuriyama Y, Yamaguchi T. Atheromatous embolism in the brain: a clinicopathologic analysis of 15 autopsy cases. Neurology 1994; 44: 1231-37.

56 Hollenhorst RW. Significance of bright plaques in the retinal arterioles. JAMA 1961; 178: 23-29.

57 Desnuelle C, Lanteri-Minet M, Hofman P, Butori C, Bedoucha P, Chatel M. Cholesterol emboli with neurologic manifestation in the spinal cord. Rev Neurol 1992; 148: 715-18.

58 Reich MP. Paraplegia following resection of an abdominal aortic aneurysm. Report of a case of atheromatous embolization to the anterior spinal artery. Vasc Surg 1968; 2: 230-34.

59 Blankenship J, Mickel S. Spinal cord infarction resulting from cardiac catheterization. Am J Med 1989; 87: 239-40.

60 Slavin R, Gonzalez-Vitale J, Marin O. Atheromatous emboli to the lumbosacral spinal cord. Stroke 1975; 6: 411-15.

61 Robinson R, Pemberton M, Goddard MJ. Myositis due to cholesterol emboli. Postgrad Med J 1993; 69: 947-49.

62 Teja K, Crampton RS. Intramural coronary arteritis from cholesterol emboli: a rare cause of unstable angina preceding sudden death. Am Heart J 1985; 110: 168-70.

63 Keon WJ, Heggtveit HA, Leduc J. Perioperative myocardial infarction caused by atheroembolism. J Thorac Cardiovasc Surg 1982; 84: 849-55.

64 Case records of the Massachusetts General Hospital. Weekly Clinicopathological Exercises. Case 11-1996. A 69-year-old man with progressive renal failure and the abrupt onset of dyspnea. N Engl J Med 1996; 334: 973-79.

65 Sabatine M, Oelberg D, Mark EJ, Kanarek D. Pulmonary cholesterol crystal embolization. Chest 1997; 112: 1687-92.

66 Vacher-Coponat H, Pache X, Dussol B, Berland Y. Pulmonary-renal syndrome responding to corticosteroids: consider cholesterol embolization. Nephrol Dial Transplant 1997; 12: 1977-79.

67 Walton TJ, Samani NJ, Andrews R. Systemic cholesterol crystal embolisation with pulmonary involvement: a fatal combination after coronary angiography. Postgrad Med J 2002; 78: 288-89.

68 Haqqie S, Urizar R, Singh J. Nephrotic-range proteinuria in renal atheroembolic disease: report of four cases. Am J Kidney Dis 1996; 28: 493-501.

69 Greenberg A, Bastacky S, Iqbal A, Borochovitz D, Johnson J. Focal segmental glomerulosclerosis associated with nephrotic syndrome in cholesterol atheroembolism: clinicopathological correlations. Am J Kidney Dis 1997; 29: 334-44.

70 Kasinath B, Corwin H, Bidani A, Korbet S, Schwartz M, Lewis E. Eosinophilia in the diagnosis of atheroembolic renal disease. Am J Nephrol 1987; 7: 173-77.

71 Cosio F, Zager R, Sharma H. Atheroembolic renal disease causes hypocomplementaemia. Lancet 1985; 2: 118-21.

72 Dahlberg P, Frecentese D, Cogbill T. Cholesterol embolism: experience with 22 histologically proven cases. Surgery 1989; 105: 737-46.

73 Scoble JE, O'Donnell PJ. Renal atheroembolic disease: the Cinderella of nephrology? Nephrol Dial Transplant 1996; 11: 1516-17.

74 Smyth JS, Scoble JE. Atheroembolism. Curr Treat Options Cardiovasc Med 2002; 4: 255-65.

75 Anderson WR, Richards AM. Evaluation of lower extremity muscle biopsies in the diagnosis of atheroembolism. Arch Pathol 1968; 86: 535-41.

76 Ripple M, Charney D, Nadasdy T. Cholesterol embolization in renal allografts. Transplantation 2000; 69: 2221-25.

77 Lai C, Randhawa P. Cholesterol embolization in renal allografts: a clinicopathologic study of 12 cases. Am J Surg Pathol 2007; 31: $536-45$.

78 de Takats D, Pollock L, O'Donnell P, Snowden S, Bewick M, Scoble JE. Is cholesterol embolic disease an unrecognized cause of renal graft dysfunction? Nephrol Dial Transplant 1996; 11: 1325-27.
79 Jennings W, Smith J, Corry R. Atheromatous embolization as a cause of increasing creatinine levels in a renal transplant patient. Transplant Proc 1990; 22: 279.

80 Scolari F, Tardanico R, Pola A, et al. Cholesterol crystal embolic disease in renal allografts. J Nephrol 2003; 16: 139-43.

81 Shappell H, Nylander W, VanBuren D, Fogo A. Adult man with primary allograft nonfunction. Am J Kidney Dis 2000; 35: 997-1001.

82 Singh I, Killen P, Leichtman A. Cholesterol emboli presenting as acute allograft dysfunction after renal transplantation. J Am Soc Nephrol 1995; 6: 165-70.

83 Ackoundou-N'Guessan C, Bismuth J, Canet S, Iborra F, Mourad G. Partial recovery of delayed graft function due to cholesterol emboli after renal transplantation. Saudi J Kidney Dis Transpl 2008; 19: 631-35.

84 Schonermarck U, Guba M, Weiss M, Illner WD, Arbogast H, Bosch T. Cholesterol atheroembolic disease in kidney allografts-case report and review of the literature. Clin Nephrol 2006; 66: 386-90.

85 Ott U, Gerth J, Grone HJ, Grone E, Wolf G. Cholesterol embolization in a renal graft. Clin Transplant 2008; 22: 677-80.

86 Siemons L, van den Heuvel P, Parizel G, Buyssens N, De Broe M, Cuykens J. Peritoneal dialysis in acute renal failure due to cholesterol embolization: two cases of recovery of renal function and extended survival. Clin Nephrol 1987; 28: 205-08.

87 Theriault J, Agharazzi M, Dumont M, Pichette V, Ouimet D, Leblanc M. Atheroembolic renal failure requiring dialysis: potential for renal recovery? A review of 43 cases. Nephron Clin Pract 2003; 94: 11-18.

88 Yucel A, Kart-Koseoglu H, Demirhan B, Ozdemir F. Cholesterol crystal embolization mimicking vasculitis: success with corticosteroid and cyclophosphamide therapy in two cases. Rheumatol Int 2006; 26: 454-60.

89 Nakayama M, Nagata M, Hirano T, et al. Low-dose prednisolone ameliorates acute renal failure caused by cholesterol crystal embolism. Clin Nephrol 2006; 66: 232-39.

90 Mann S, Sos TA. Treatment of atheroembolization with corticosteroids. Am J Hypertens 2001; 14: 831-34.

91 Woolfson RG, Lachmann H. Improvement in renal cholesterol emboli syndrome after simvastatin. Lancet 1998; 351: 1331-32.

92 Keen R, McCarthy W, Shireman P, et al. Surgical management of atheroembolization. J Vasc Surg 1995; 21: 773-80.

93 Matchett W, McFarland D, Eidt J, Moursi M. Blue toe syndrome: treatment with intra-arterial stents and review of therapies. J Vasc Interv Radiol 2000; 11: 585-92.

94 Carroccio A, Olin JW, Ellozy SH, et al. The role of aortic stent grafting in the treatment of atheromatous embolization syndrome: results after a mean of 15 months follow-up. J Vasc Surg 2004; 40: 424-29.

95 Rocha-Singh KJ, Eisenhauer AC, Textor SC, et al. Atherosclerotic peripheral vascular disease symposium II: intervention for renal artery disease. Circulation 2008; 118: 2873-78.

96 Polu KR, Wolf M. Clinical problem-solving. Needle in a haystack. N Engl J Med 2006; 354: 68-73.

97 Scoble JE. Is nihilism in the treatment of atheroembolic disease at an end? Am J Kidney Dis 1999; 33: 975-76.

98 Cogan E, Schandene L, Papadopoulos T, Crusiaux A, Goldman M. Interleukin-5 production by $\mathrm{T}$ lymphocytes in atheroembolic disease with hypereosinophilia. J Allergy Clin Immunol 1995; 96: 427-29.

99 LaRosa J, Grundy S, Waters D, et al. Intensive lipid lowering with atorvastatin in patients with stable coronary disease. N Engl J Med 2005; 352: 1425-35.

100 Pedersen TR, Faergeman O, Kastelein JJ, et al. High-dose atorvastatin vs usual-dose simvastatin for secondary prevention after myocardia infarction: the IDEAL study: a randomised controlled trial. JAMA 2005; 294: 2437-45.

101 Reimers B, Corvaja N, Moshiri S, et al. Cerebral protection with filter devices during carotid artery stenting. Circulation 2001; 104: 12-15.

102 Henry M, Henry I, Klonaris C, et al. Renal angioplasty and stenting under protection: the way for the future? Catheter Cardiovasc Interv 2003; 60: 299-312 